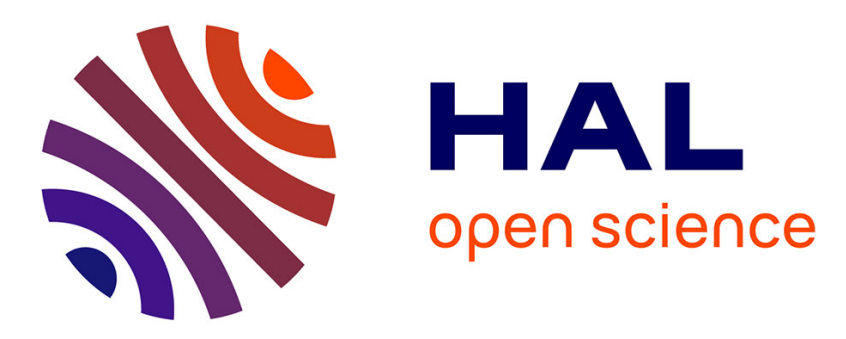

\title{
Improved dispersion of carbon nanotubes in poly(vinylidene fluoride) composites by hybrids with core-shell structure
}

Benhui Fan, Xiaoxin Lu, Zhimin Dang, Yuan Deng, Xiying Zhou, Delong He, Jinbo Bai

\section{To cite this version:}

Benhui Fan, Xiaoxin Lu, Zhimin Dang, Yuan Deng, Xiying Zhou, et al.. Improved dispersion of carbon nanotubes in poly(vinylidene fluoride) composites by hybrids with core-shell structure. Journal of Applied Polymer Science, 2018, 135 (3), 10.1002/app.45693 . hal-01842433

\section{HAL Id: hal-01842433 \\ https://hal.science/hal-01842433}

Submitted on 3 Dec 2020

HAL is a multi-disciplinary open access archive for the deposit and dissemination of scientific research documents, whether they are published or not. The documents may come from teaching and research institutions in France or abroad, or from public or private research centers.
L'archive ouverte pluridisciplinaire HAL, est destinée au dépôt et à la diffusion de documents scientifiques de niveau recherche, publiés ou non, émanant des établissements d'enseignement et de recherche français ou étrangers, des laboratoires publics ou privés. 


\section{Improved Dispersion of Carbon Nanotubes in Polyvinylidene}

\section{Fluoride Composites by Hybrids with Core-Shell Structure}

Benhui Fan ${ }^{1}$, Xiaoxin Lu' ${ }^{1}$, Zhimin Dang ${ }^{2}$, Yuan Deng ${ }^{3}$, Xiying Zhou ${ }^{4}$, Delong $\mathrm{He}^{1} *$ and Jinbo $\mathrm{Bai}^{1}{ }^{*}$

${ }^{1}$ Laboratoire Mécanique des Sols, Structures et Matériaux (MSSMat), CNRS UMR 8579, Ecole CentraleSupelec, Université Paris Saclay, Grande Voie des Vignes, 92290, Chatenay-Malabry, France

${ }^{2}$ State Key Laboratory of Power System, Department of Electrical Engineering, Tsinghua University, Beijing, 100084, China

${ }^{3}$ Beijing Key Laboratory for Advanced Functional Materials and Thin Film Technology, School of Materials Science and Engineering, Beihang University, Beijing 100191, China

${ }^{4}$ Shanghai University of Engineering Science, 333 Longten road, Shanghai 201620

\section{* Corresponding author:}

Prof. Jinbo Bai

Email: jinbo.bai@centralesupelec.fr

Phone: +33 (0)1 41131316

Fax: $+33(0) 141131460$

Dr. Delong He

Email: Delong.he@centralesupelec.fr

Phone: +33(0)141131526

Fax: +33 (0)1 41131460 


\begin{abstract}
Core-shell structure hybrids of $\mathrm{CNTs} / \mathrm{BaTiO}_{3}$ (H-CNT-BT) and commercial multi-wall carbon nanotubes (CNTs) are respectively incorporated into polyvinylidene fluoride (PVDF) for preparing the composites near the percolation thresholds. A comprehensive investigation for CNT's dispersion and composite's conductivity is conducted between H-CNT-BT/PVDF and CNT/PVDF at different depths vertical to the injection's direction. Gradual increases of the conductivity in two composites are observed from the out-layer to the core part which infers an inhomogeneous CNT's dispersion in the interior of composites due to their migration under flow during the injection. However, the use of H-CNT-BT fillers with core-shell structure enables to reduce this inhomogeneous dispersion in the composite. Furthermore, the conductive network of CNTs in H-CNT-BT/PVDF is less sensitive to the thermal treatment than the one in CNT/PVDF composite, which infers the core-shell structure of hybrids can ameliorate the sensitivity of the conductive network.
\end{abstract}

Key words: CNT's dispersion, injection direction, sensitivity of the conductive network 


\section{Introduction}

Carbon nanotube $(\mathrm{CNT})$, with one-dimensional structure and high electrical conductivity $\left(10^{4} \mathrm{~S} / \mathrm{m}\right)$ is a kind of excellent conductive fillers which can achieve polymer composite with high electrical conductivity by low volume fractions incorporation. ${ }^{[1-5]}$ This outstanding performance is based on the percolation theory: ${ }^{[6-8]}$ namely, a continuous conductive network can be formed in the composite when the volume fraction is approaching to a certain value, percolation threshold $\left(f_{c}\right)$, and then a strong polarization by electron's tunneling effect happens at the interfacial area of CNT and polymer which significantly increases electrical conductivity at low frequency (from $10^{-2}$ to $1000 \mathrm{~Hz}$ ). However, this increase of the conductivity caused by the interfacial polarization is sensitive to the external stimulation. Moreover, it also strongly depends on the processing methods. ${ }^{[9-11]}$ There are various processing methods to prepare CNT reinforced composites including solution casting, melting blending and in-situ polymerization, etc, but the most widely-used method for manufacturing is melting blending as the result of numerous advantages such as high speed, simplicity and easy integration into standard industrial facilities. ${ }^{[12,13]}$ The procedure of melting blending generally consists of two following steps: the molten polymer is mixed with CNTs by the shear of screws, and afterwards the mixture is shaped by extrusion-injection molding. Due to large aspect ratio of CNTs as well as the shearing forces of mold surface, CNTs are unavoidably orientated under flow during injection molding, which makes the dispersion of CNTs inhomogeneous in the composite vertical to the injection's direction. Large amounts of studies have been focused on how to address this problem including optimizing the technique parameters of the extrusion-injection such as adjusting mold's shape and injection parameters as well as increasing interaction between polymer and CNT by surface modification etc. ${ }^{[14-20]}$

In this study, a novel hybrid of $\mathrm{BaTiO}_{3}$ (BT) and CNT (H-CNT-BT) with core-shell structure prepared by chemical vapor disposition (CVD) is used to modify the inhomogeneous dispersion of CNTs in the composite by double dispersal of BT carriers. The polymer matrix selected is polyvinylidene fluoride (PVDF), a kind of 
semi-crystalline thermal plastic polymer with the crystallization temperature of 150 ${ }^{\circ} \mathrm{C}$ and the melting point of $170{ }^{\circ} \mathrm{C}$. ${ }^{[21-23]}$ Meanwhile, commercial CNT and PVDF composite (CNT/PVDF) is also prepared for comparing with H-CNT-BT/PVDF. Frequency dependence of the conductivity $(\sigma)$ is measured at different depths of the two composites by abrasive paper's polishing in order to compare the $\sigma$ from out-layer to core part vertical to the injection's direction. In addition, a thermal treatment at $150{ }^{\circ} \mathrm{C}$ is also conducted to study the sensitivity of CNT conductive network near $f_{\mathrm{c}}$ of the two samples. By analyzing the $\sigma$ at different depths, it can be found that H-CNT-BT with core-shell structure can not only modify CNT's dispersion but also release the sensitivity of conductive network to the thermal treatment.

\section{Experiment and characterization}

2.1 Materials and methods: BT, iron nitride nonahydrate $\left(\mathrm{Fe}\left(\mathrm{NO}_{3}\right)_{3} \cdot 9 \mathrm{H}_{2} \mathrm{O}\right)$ and N,N-dimethylformamide (DMF) were purchased from Sigma Aldrich. BT particles are with tetragonal crystal phase and the diameter range is about 1-2 $\mu \mathrm{m}$. PVDF (Kynar 721) is provided from Arkema Group, France. Its melt volume-flow rate (MVR) is $10 \mathrm{~cm}^{3} / 10 \mathrm{~min}$. CNTs used in the CNT/PVDF composite are multi-wall carbon nanotubes provided by Shenzhen nanotech Port Company (China).

The H-CNT-BT hybrids were synthesized by CVD process at $650{ }^{\circ} \mathrm{C}$ for $30 \mathrm{~min}$. Acetylene $\left(\mathrm{C}_{2} \mathrm{H}_{2}\right)$ and $\mathrm{Fe}\left(\mathrm{NO}_{3}\right)_{3} \cdot 9 \mathrm{H}_{2} \mathrm{O}$ were used as the carbon source and the catalyst precursor, respectively. The detail of the synthesis can be found in previous papers. ${ }^{[22,}$ ${ }^{23,25]}$ The weight content of CNTs in H-CNT-BT hybrids was around 0.11 which was tested by a thermal analyser (NETZSCH STA $449 \mathrm{~F} 3$ ) from 30 to $800{ }^{\circ} \mathrm{C}$, under $\mathrm{N}_{2}$ and $\mathrm{O}_{2}$ flow rate of $60: 60 \mathrm{ml} / \mathrm{min}$ and with the heat rate of $20{ }^{\circ} \mathrm{C} / \mathrm{min} .{ }^{[22]}$ The two samples selected for this study were CNT/PVDF-8\% and H-CNT-BT/PVDF-9.5\%, respectively. $8 \%$ and $9.5 \%$ indicated the volume fractions of CNTs and H-CNT-BT used in PVDF matrix. Meanwhile, CNT's volume fraction in H-CNT-BT/PVDF-9.5\% is $2.6 \%$. The reason of selecting these two volume fractions is that they are respectively near $f_{\mathrm{c}}$ in the systems and the linear fittings by percolation theory for these two composites could be found in pervious papers, respectively. ${ }^{[24,26]}$ The 
preparation for the composite was divided into two steps which were shown in the schematic diagram of Fig.1. Concretely, the pre-calculated fillers (CNT or H-CNT-BT) were firstly disposed in DMF by an ultrasonic bath for $30 \mathrm{~min}$ in order to reduce CNT's agglomeration. Then PVDF powder was added into the mixture and stirred magnetically for $2 \mathrm{~h}$ at $70{ }^{\circ} \mathrm{C}$. The mixed slurry was coated on the glass substrate and put into the oven at $70{ }^{\circ} \mathrm{C}$ for $2 \mathrm{~h}$ in order to evaporate DMF solvent. Secondly, the obtained film was cut into pieces and put into a co-rotating, conical, two-screw micro-extruder/compounder (Micro 5cc Twin Screw Compounder, DSM). The blending was conducted at $230{ }^{\circ} \mathrm{C}$ for $1 \mathrm{~h}$ with the speed of $60 \mathrm{rpm}$ under the $\mathrm{Ar}$ protection atmosphere. Bone-shaped slabs with the thickness of $1.45 \mathrm{~mm}$ were fabricated by the extrusion-injection way. The temperatures for the injection nozzle and mold holder were set at $240{ }^{\circ} \mathrm{C}$ and $60{ }^{\circ} \mathrm{C}$, respectively.

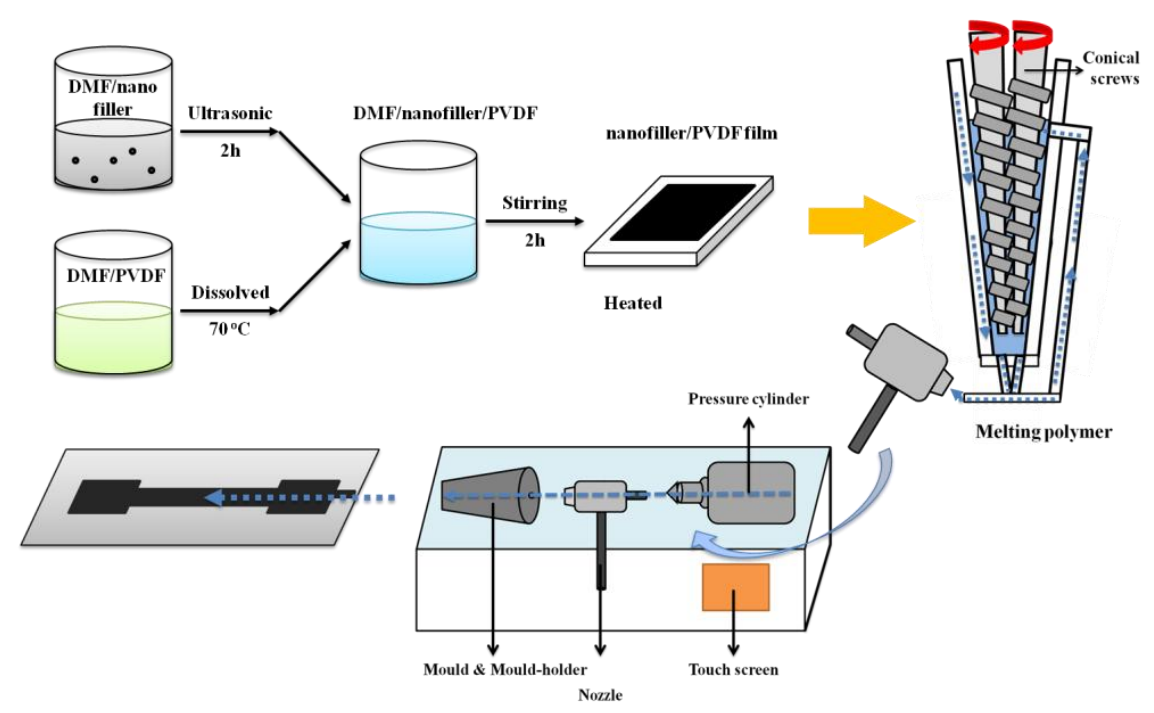

Fig.1 Schematic diagram of the preparation of the composite

2.2 Characterization: The as-prepared samples were characterized by the following techniques: The morphology characterizations for H-CNT-BT and composites were conducted by the scanning electron microscope (SEM) (LEO Gemini 530). The composites were broken after being impregnated in liquid nitrogen for at least $5 \mathrm{~min}$, and the fractured surfaces were coated with a thin layer of platinum to increase the samples' surface conductivity. An acceleration voltage of $5 \mathrm{kV}$ was used for the 
measurement. The composite's $\sigma$ at a wide range of frequencies was characterized by an impedance analyzer (Solartron 1260) with the voltage of $1 \mathrm{~V}$ at room temperature $\left(23{ }^{\circ} \mathrm{C}\right)$. Before the measurement, the silver paste was applied on double faces of the sample for reducing contacting resistance with the electrodes. Each sample is considered as a plane capacitor and can be described by a parallel resistor-capacitor (RC) circuit system. The complex conductivity $\left(\sigma^{*}\right)$ is calculated as follows: $\sigma^{*}=\sigma^{\prime}-\mathrm{j} \sigma^{\prime \prime}$, where $\sigma^{\prime}$ and $\sigma^{\prime \prime}$ correspond to the real and imaginary parts of the

complex $\sigma^{*}$ respectively. $\mathrm{j}=(-1)^{\frac{1}{2}}$ is the imaginary unit. For studying the influence of the thermal treatment on CNT's conductive network in the composite, the sample was annealed at $150{ }^{\circ} \mathrm{C}$ for $30 \mathrm{~min}$ and then cooled naturally to the room temperature. The measurement of the $\sigma$ was conducted at room temperature.

\section{Results and discussions}

3.1 The morphology of H-BT-CNT and two composites: The SEM images for synthesized H-CNT-BT are presented in Fig.2 (a) and (b). It can be found that the core-shell structure is universal in the hybrids and as shown in Fig.2 (b), CNTs directly grow on the surface of BT particles as marked by the white cycle. Some CNTs are relatively straight while others are with curves. The average length of CNTs is hard to be evaluated from the SEM image because parts of CNTs wrap around the BT particle. Fig.2 (c) and (d) show the morphology of the fracture surface for H-CNT-BT/PVDF-9.5\% and the CNT/PVDF-8\%, respectively. It can be seen that CNTs are well dispersed by micro-compounder, but as shown in Fig.2 (c), the core-shell structure of H-CNT-BT is partially destroyed during the blending but some remained structures can still be figured out as marked in white cycles. Actually, it is hard to tell the difference between Fig.2 (c) and Fig.2 (d) since BT particles and PVDF's fracture area are resemble. Moreover, SEM images just present the dispersion of CNTs in a partial and limited area, which is not comprehensive enough for understanding the global dispersion of CNTs in the whole composite. Therefore, in order to further study the different dispersion, measuring and analyzing the $\sigma$ at 
different depths vertical to injection's direction can be a simple and efficient way which will be discussed in the following sections.

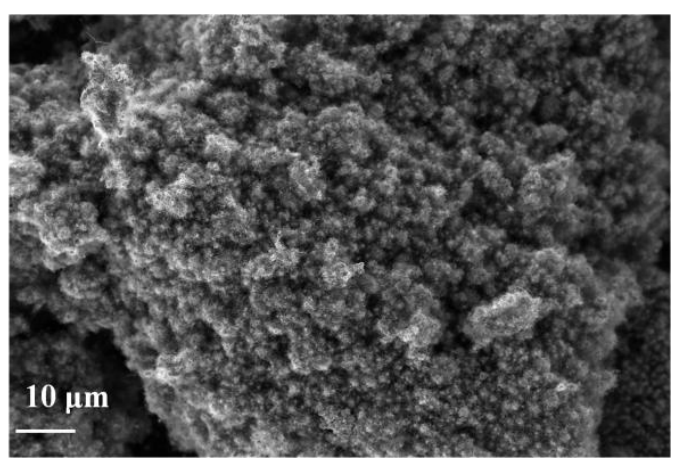

(a)

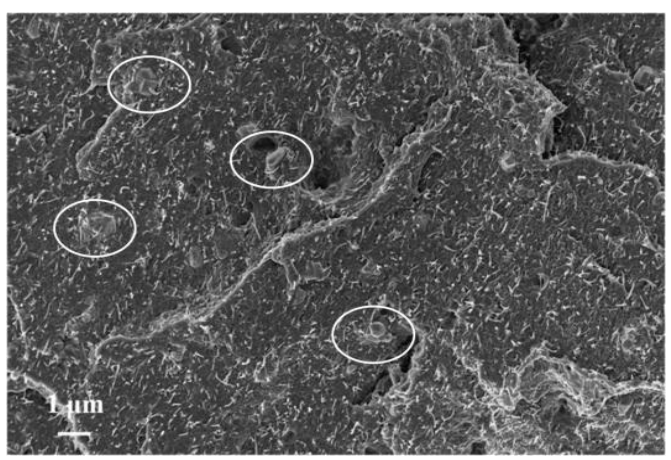

(c)

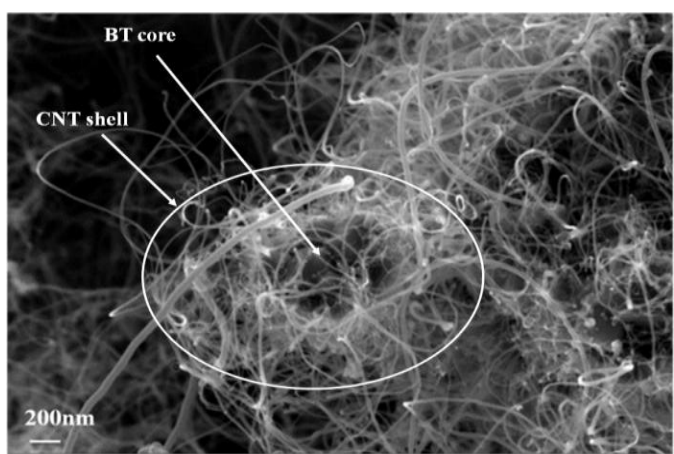

(b)

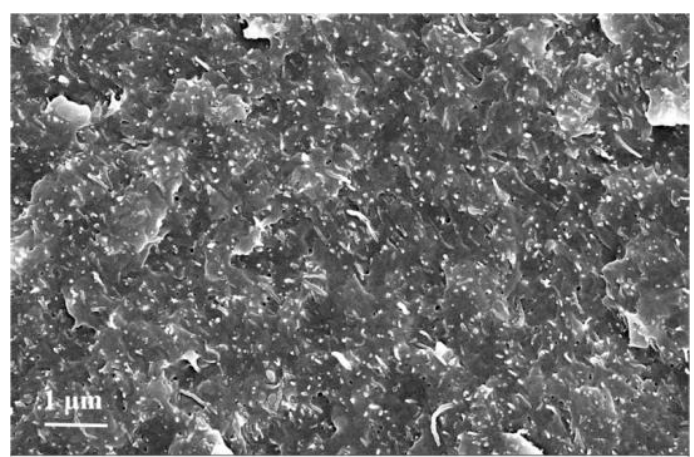

(d)

Fig.2 (a) and (b): SEM image for H-CNT-BT. (c) The fracture surface for the H-CNT-BT/PVDF-9.5\%. (d) The fracture surface for the CNT/PVDF-8\%.

3.2 Frequency dependence of the conductivity: Due to the migration and orientation of CNTs under the shearing force of mold's surfaces during the injection, CNT's dispersions are various in the interior of the composite. Thus, the $\sigma$ and the sensitivity of conductive network to the thermal treatment will be compared at different depths of the composite.

First, in the case of CNT/PVDF-8\% composite: two samples from one slab are selected for the study. One is for the measurement of the $\sigma$ without thermal treatment; the other is for the measurement after thermal treatment. The selected samples should have similar $\sigma$ as presented in Fig.3. An abrasive paper is used to polish both faces of the specimen simultaneously and the removed thickness is controlled by $0.1 \mathrm{~mm}$ each 
time. After each polishing, the $\sigma$ is measured and the results are presented in Fig.4.

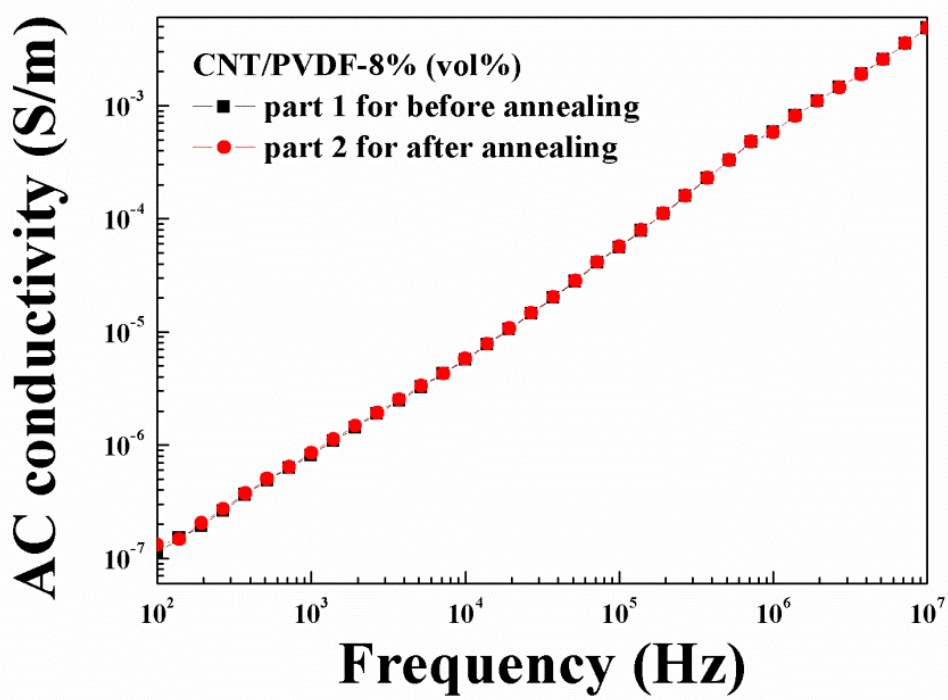

Fig.3 Frequency dependence of the conductivity for two counterparts of CNT/PVDF-8\%.

For CNT/PVDF-8\% without the thermal treatment, as shown in Fig.4, we find that as the thickness reduces from the out-layer to the core part $(1.44 \mathrm{~mm} \rightarrow 0.3 \mathrm{~mm})$, the $\sigma$ increases gradually until to the core part where the value of $\sigma$ is several magnitudes larger than that of the out-layer. Meanwhile, the $\sigma$ at the core part also shows less frequency-dependence than that at other depths. This obvious difference in $\sigma$ in one specimen infers the inhomogeneous dispersion of CNTs in the composite vertical to injection's direction. A schematic diagram is presented in the right part of Fig.5 to illustrate this variety of the $\sigma$ at $100 \mathrm{~Hz}$. As mentioned before: when the molten composite is injected into a mold by fast speed, two top surfaces of the composite contact the mold directly which causes an orientated and aligned dispersion of CNTs along the injection's direction due to the shearing force of mold's surface. Instead, in the core part without the direct contact from the mold, the orientation is weakened by the relatively high viscosity of molten composite so that the dispersion of CNTs in the core part becomes more random. This random dispersion of CNTs will increase the possibility of mutual contact between adjacent CNTs and strengthens the 
interfacial polarization by the tunneling effect. Consequently, the $\sigma$ increases at the low frequency. Therefore, after comparing the $\sigma$ at different depths, it can be found that the extrusion-injection can cause an inhomogeneous dispersion of CNTs in the composite which depends on the depth of the sample vertical to injection's direction: The CNT's dispersion is more orientated at the top surface while more random in the core part.

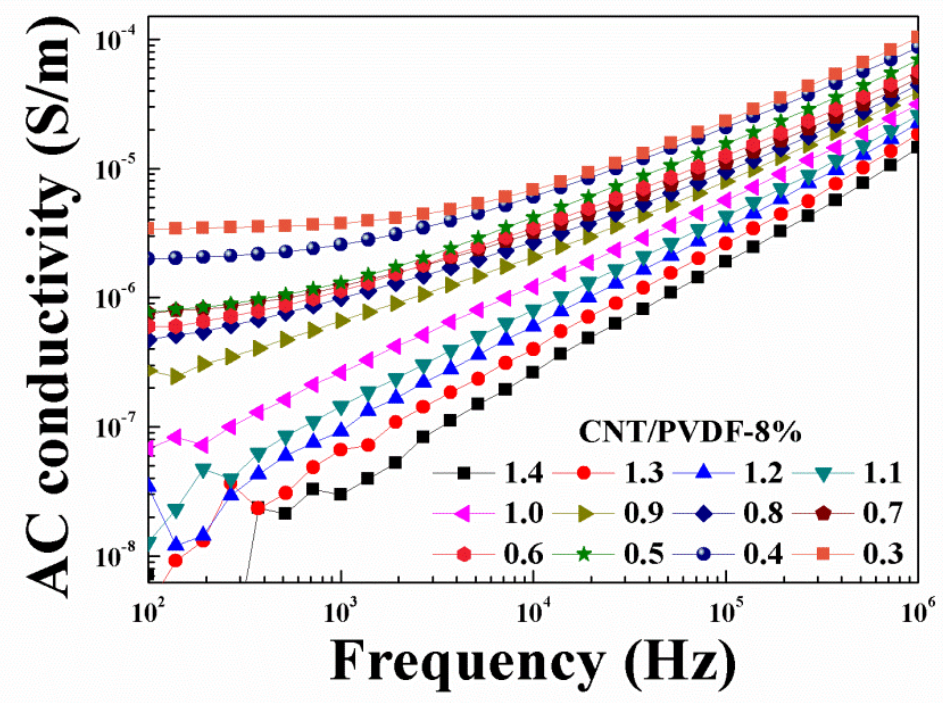

Fig.4 Frequency dependence of the conductivity for the CNT/PVDF-8\% at different depths without the thermal treatment.

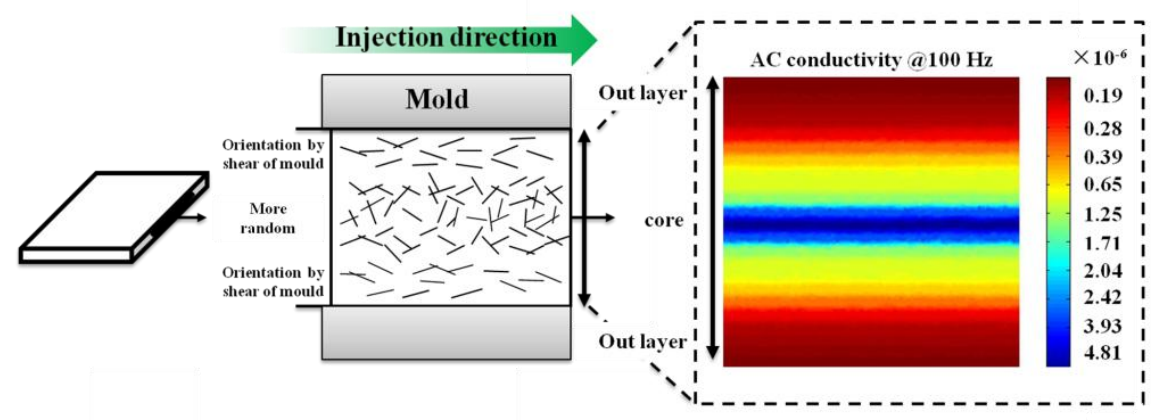

Fig.5 The variety of CNT's dispersion in the sample from the out-layer to the core part vertical to the injection direction. 
In order to study the sensitivity of the conductive network to the thermal treatment for CNT/PVDF-8\%, the other sample is annealed for $30 \mathrm{~min}$ at $150{ }^{\circ} \mathrm{C}$ which corresponds to PVDF's crystallization temperature. After cooled naturally to the room temperature, the same measurement is conducted for this sample and the results are presented in the Fig.6. Comparing with Fig. 4, it can be found that the thermal treatment can increase the $\sigma$ at each thickness, which infers that the conductive network of CNT is sensitive to the thermal treatment. Meanwhile, this sensitivity also depends on the dispersion of CNTs. In the core part, the conductive network is even more sensitive than the out-layer since the value of the $\sigma$ increases faster in the core part. Hence, CNT's dispersion in a specimen processed by extrusion-injection is not only inhomogeneous as reported by others papers ${ }^{[27,28]}$ and but also aggravates the sensitivity of the conductive network to the thermal treatment.

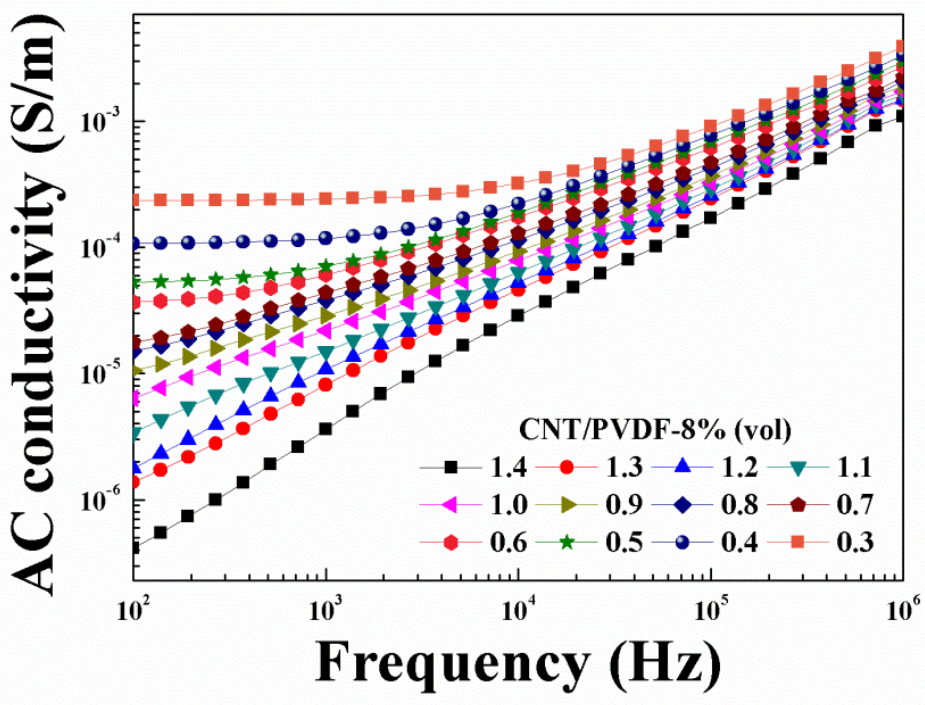

Fig.6 Frequency dependence of the conductivity for CNT/PVDF-8\% at different depths after the thermal treatment.

For the sample of H-CNT-BT/PVDF-9.5\%, the similar measurements are conducted: First, two counterparts from one slab with similar $\sigma$ are selected and the frequency dependence of the $\sigma$ is presented in Fig. 7 for the reference. 


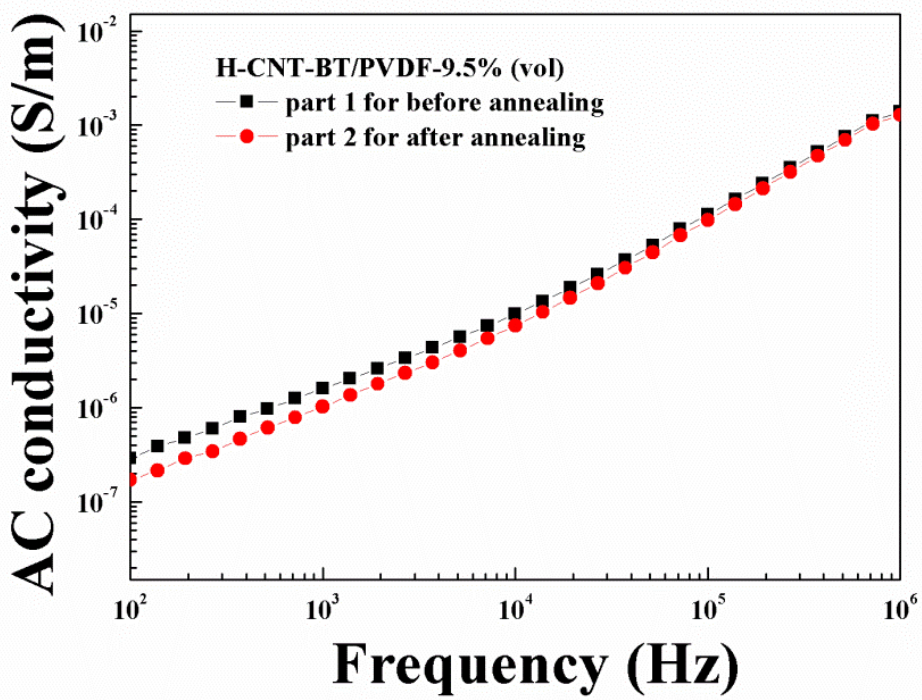

Fig.7 Frequency dependence of the conductivity for the two counterparts of H-CNT-BT/PVDF-9.5\%.

The results for the $\sigma$ of H-CNT-BT/PVDF-9.5\% with and without the thermal treatment are plotted in Fig.8 (a) and (b), respectively. As shown in Fig.8 (a), the variety of CNT's dispersion in H-CNT-BT/PVDF-9.5\% only happens at the top surface which is different from the case of CNT/PVDF-8\%. When the H-CNT-BT/PVDF-9.5\% sample is abrased into $1.2 \mathrm{~mm}$ in the thickness, the $\sigma$ becomes stable. Even though the thickness reduces further, the value of $\sigma$ does not change obviously. This infers that the existance of BT particles can effectively improve the homogeneity of CNT's dispersion in the interior of the composite. This improvement is possibly attributed to the core-shell sctrcture of hybrids where the CNTs is located individually on BT carriers instead of an initially entangled state before being incorporated into PVDF matrix. After blending, CNTs can be detached from the carriers and dispersed into the matrix in a more homogeneous state. Furthermore, the results after thermal treatment in Fig.8 (b) indicate that the sensitivity of CNT's conductive network to the thermal treatment is not as significantly as the case of CNT/PVDF-8\% as shown in Fig 6. The increase of the $\sigma$ after thermal treatment also just appears at the top surface. We plot the results of 
H-CNT-BT/PVDF-9.5\% and CNT/PVDF-8\% together in Fig.9 for the compasion.

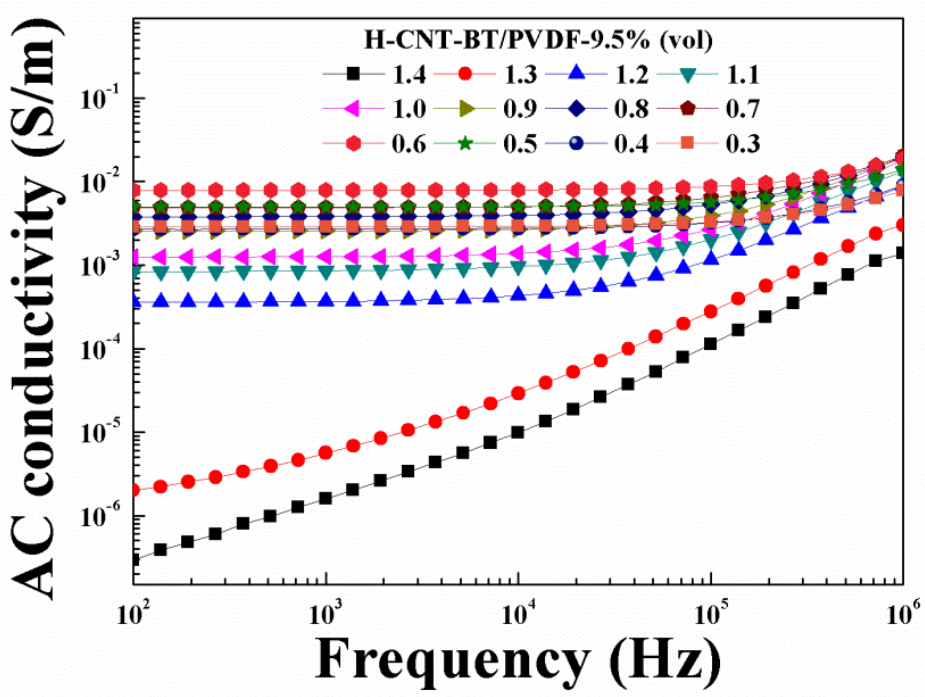

(a)

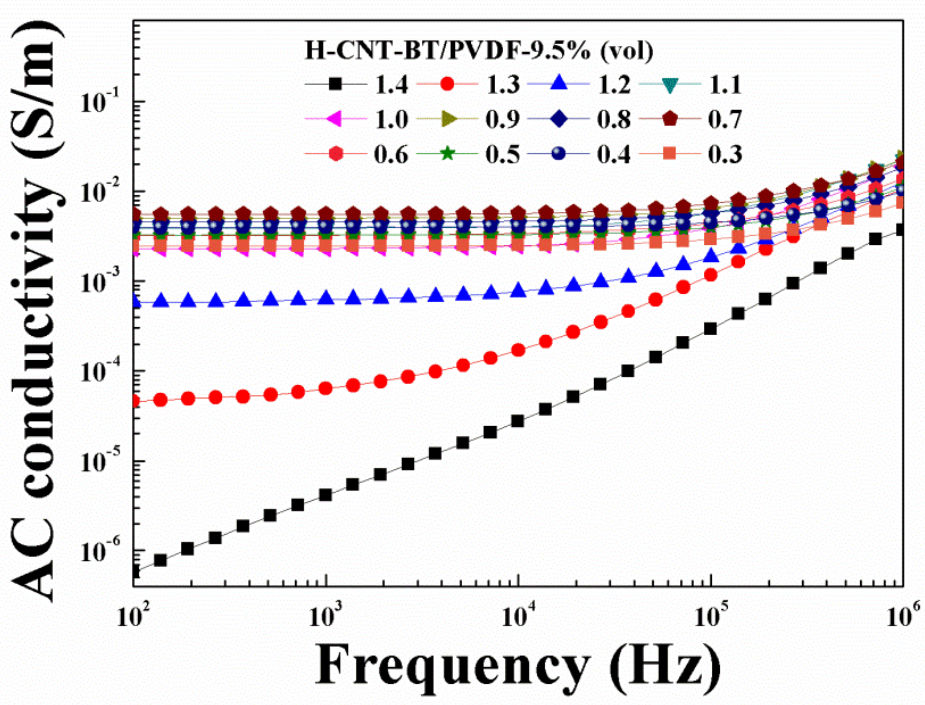

(b)

Fig.8 Frequency dependence of the conductivity for H-CNT-BT/PVDF-9.5\% at different depths. (a) without thermal treatment and (b) after thermal treatment 


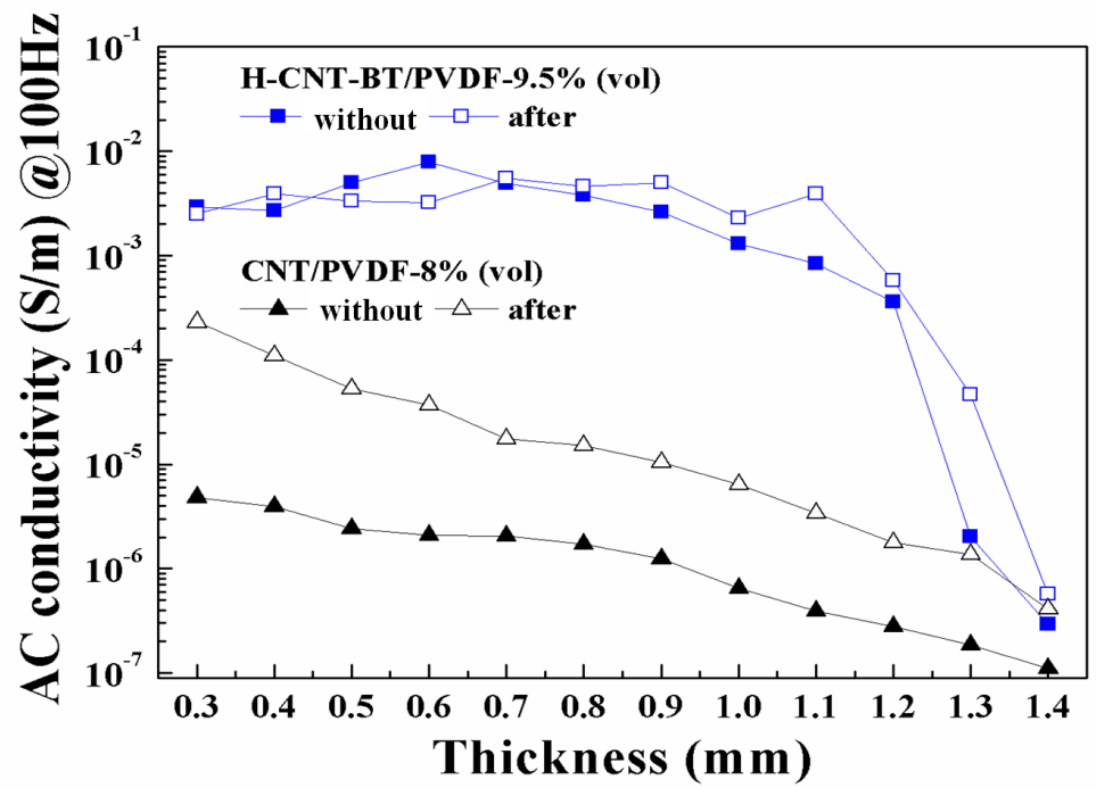

Fig.9 The comparison of the conductivities at different depths for H-CNT-BT/PVDF-9.5\% and CNT/PVDF-8\% without and after thermal treatment, respectively.

3.3 The sensitivty of conductive network to the thermal treatment: As shown in Fig.9, we find that only at the top surface of H-CNT-BT/PVDF-9.5\%, the conductive network is sensitive to the thermal treatment. Instead, for the CNT/PVDF-8\% it is sensitive in all depths of the sample. This infers that the core-shell structure of hybrids can help to decrease the sensitivity of CNT's conductive network to the thermal treatment. Besides improving CNT's dispersion and effectively avoiding the aggregations, the in-situ growth of CNTs on BT particles favors to stablizing CNTs in the PVDF and sustaining CNT's network during the extrusion-injection procedure. After the thermal treatment, the conductive networks is more difficult to reform with BT paticles supporting than the one in CNT/PVDF which helps to produce a more stable conductive network in H-CNT-BT/PVDF composite. A sechematic diagram in Fig.10 is used to illustrate the mentioned advantages of H-CNT-BT's structure. Therefore, after studying the $\sigma$ at different depths without and after thermal treatment, it can be found that H-CNT-BT with core-shell structure can not only improve CNT's dispersion but also release the sensitivity of CNT's conductive network to the thermal treatment. 


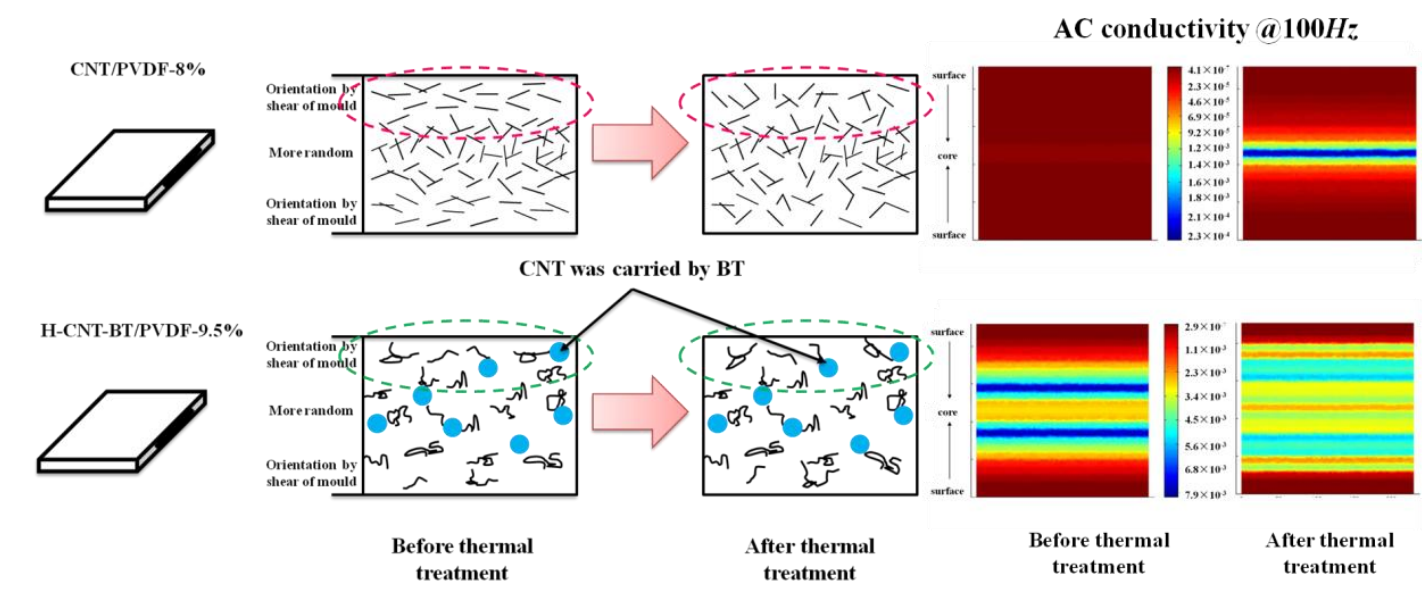

Fig.10 The influence of hybrid's structure on the conductivity.

\section{Conclusion}

The comprehensive investigation for frequency dependence of the conductivity at different depths in the composite indicates that CNT's dispersion is inhomogeneous in the composite prepared by the extrusion-injection. At the out-layer, CNTs are more orientated along the injection's direction while in the core part, the dispersion is more random. By designing the hybrids with core-shell structure, this inhomogeneous dispersion caused by injection molding can be ameliorated. Moreover, the H-CNT-BT not only favors to improve the dispersion of CNTs in PVDF matrix but also reduce the sensitivty to the thermal treatment due to the sustainment of BT particles for the conductive networks.

\section{Acknowledgements}

Benhui Fan thanks the suggestion of the measurement from Prof. G. H. Hu and SEM image of CNT/PVDF-8\% from Dr. J. K. Yuan.

\section{References}

[1] Byrne M, Gun'ko Y. Recent advances in research on carbon nanotube polymer composites. Advance Materials 2010. 22. 15. 
[2] Arjmand M, Sundararaj U. Effects of nitrogen doping on X-band dielectric properties of carbon nanotube/polymer nanocomposites. ACS applied materials \& interfaces 2015.7. 32.

[3] Chen Z, Xie L, Huang X, Li S, Jiang P. Achieving large dielectric property improvement in polymer/carbon nanotube composites by engineering the nanotube surface via atom transfer radical polymerization. Carbon 2015. 95. 895.

[4] Jinkai Yuan, Shenghong Yao, Weilong Li, Alain Sylvestre and Jinbo Bai, Anisotropic Percolation of SiC-Carbon Nanotube Hybrids: A New Route toward Thermally Conductive High- $k$ Polymer Composites, The Journal of Physical Chemistry C, 2017, DOI: 10.1021/acs.jpcc.7b03372

[5] I. Burmistrov, N. Gorshkov, I. Ilinykh, D. Muratov, E. Kolesnikov, S. Anshin, I. Mazov, J.-P. Issi, D. Kusnezov, Improvement of carbon black based polymer composite electrical conductivity with additions of MWCNT. Composites Science and Technology 2016. 129. 79-85.

[6] Nan CW, Shen Y and Ma J. Physical properties of composites near percolation. The Annual Review of materials Research 2010. 40. 131.

[7] Qin Chen, Yang Shen, Shihai Zhang and Qiming Zhang, Polymer-based dielectrics with high energy storage density, The Annual Review of Materials Research, 2015, 45, 433-58

[8] Dang ZM, Yuan JK, Yao SH and Liao RJ. Flexible nanodielectric materials with high permittivity for power energy storage. Advanced. Materials 2013. 25. 44 .

[9] Deng H, Lin L, Ji MZ, Zhang SM, Yang MB and Fu Q. Progress on the morphological control of conductive network in conductive polymer composites and the use as electroactive multifunctional materials. Progress in Polymer Science 2014. 39. 4.

[10]

Beate Krause Petra Pötschke, Evgeniy Ilin, Mikhail Predtechenskiy, Melt mixed SWCNT-polypropylene composites with very low electrical 
percolation. Polymer, 2016. 98 45-50.

[11] Deng H, Skipa T, Bilotti E, Zhang R, Lellinger D, Mezzo L, Fu Q, Alig I and Peijs T. Preparation of high-performance conductive polymer fibers through morphological control of networks formed by nanofillers. Advanced Functional materials 2010. 20. 9.

[12] Dang ZM, Yuan JK, Zha JW, Zhou T, Li ST, Hu GH. Fundamentals, processes and applications of high-permittivity polymer-matrix composites. Progress in Materials Science 2012. 74. 4.

[13] Garima Mittal, Vivek Dhand, Kyong Yop Rhee, Soo-Jin Park, Wi Ro Lee, A review on carbon nanotubes and graphene as fillers in reinforced polymer nanocomposites. Journal of Industrial and Engineering Chemistry. 2015. 21. $11-25$.

[14] Bright PF, Crowson RJ and Folkes MJ. A study of the effect of injection speed on fiber orientation in simple mouldings of short glass fiber-filled polypropylene. Journal of materials science 1978. 13. 2497.

[15] Alig I, Potschke P, Lellinger D, Skipa T, Pegel S, Kasaliwal GR and T. Villmow. Establishment, morphology and properties of carbon nanotube networks in polymer melts. Polymer 2012. 53. 1.

[16] Pegel S, Potschke P, Petzold G, Alig I, Dudkin SM, Lellinger D. Dispersion, agglomeration, and network formation of multiwalled carbon nanotubes in polycarbonate melts. Polymer 2008. 49. 4.

[17] Li SN, Li B, Li ZM, Fu Q, Shen KZ. Morphological manipulation of carbon nanotube/polycarbonate/polyethylene composites by dynamic injection packing molding. Polymer 2006. 47. 13.

[18] Villmow T, Pegel S, Potschke P, Wagenknecht U. Influence of injection molding parameters on the electrical resistivity of polycarbonate filled with multi-walled carbon nanotubes. Composites Science and Technology 2008. 68. 3 .

[19] Goutam Chakraborty, Kajal Gupta, Dipak Rana, Ajit Kumar Meikap. 
Electrical Transport Properties of the Composite of Multiwall Carbon Nanotube-Polypyrrole-Polyvinyl Alcohol Below Room Temperature. Polymer Composites. 2012. 33. 3

[20] Goutam Chakraborty, Kajal Gupta, Dipak Rana and Ajit Kumar Meikap. Dielectric relaxation in polyvinyl alcohol-polypyrrole-multiwall carbon nanotube composites below room temperature. Advances in Natrual Science: Nanoscience and Nanotechnology. 2013. 4. 025005

[21] Bohlen M and Bolton K. Inducing the $\beta$-phase of poly(vinylidene fluoride) a review. Annual review of nanoscience and nanotechnology 2015. 1150110

[22] Fan $\mathrm{BH}$ and $\mathrm{Bai}$ J. Composites of hybrids $\mathrm{BaTiO}_{3} /$ carbon nanotubes/polyvinylidene fluoride with high dielectric properties. Journal of Physics D: Applied Physics 2015. 48. 455303.

[23] Fan BH, Salem D, Haghi-Ashtiani P and Bai J. Influence of inter structure of two-phase hybrid fillers $\mathrm{BaTiO}_{3}$ and carbon nanotubes on the dielectric properties of polyvinylidene fluoride matrix composites. Journal of Advanced Physics 2015. 4. 1.

[24] Yuan JK, Yao SH, Dang ZM, Sylvestre A, Genestoux M and Bai J. Giant Dielectric Permittivity Nanocomposites: Realizing True Potential of Pristine Carbon Nanotubes in Polyvinylidene Fluoride Matrix through an Enhanced Interfacial Interaction. The Journal of Physical Chemistry C 2011. 115. 13.

[25] He DL, Li H, Bai J. Experimental and numerical investigation of the position-dependent growth of carbon nanotube-alumina microparticle hybrid structures in a horizontal CVD reactor. Carbon 2011. 49. 5359.

[26] Fan BH, Bedoui F, Weigand S and Bai J. Conductive network and $\beta$ polymorph content evolution caused by thermal treatment in carbon nanotubes- $\mathrm{BaTiO}_{3}$ hybrids reinforced polyvinylidene fluoride composites. The Journal of Physical Chemistry C 2016. DOI: 10.1021/acs.jpcc.6b01745

[27] Mahmoodi M, Arjmand M, Sundararaj U, Park S. The Electrical Conductivity and Electromagnetic Interference Shielding of Injection Molded Multi-walled 
Carbon Nanotube/Polystyrene Composites. Carbon 2011. 50. 1455-1464.

[28] Arjmand M, Apperley T, Okoniewski M, Sundararaj U. Comparative Study of Electromagnetic Interference Shielding Properties of Injection Molded versus Compression Molded Multi-walled Carbon Nanotube/Polystyrene Composites. Carbon 2012. 50. 5126-5134.

\section{Abstract Image}

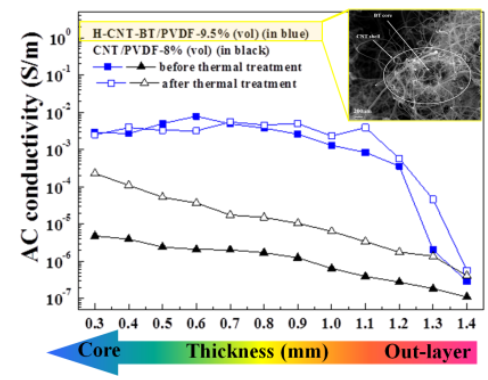

